\title{
OBSTRUCTIVE APNEAS IN A MOUSE MODEL OF CONGENITAL CENTRAL HYPOVENTILATION SYNDROME
}

Amélia Madani1 ${ }^{1, *}$, Gabriel Pitollat ${ }^{2, *}$, Eléonore Sizun ${ }^{1}$, Laura Cardoit ${ }^{2}$, Maud Ringot $^{1}$, Thomas Bourgeois $^{1}$, Nelina Ramanantsoa ${ }^{1}$, Christophe Delclaux ${ }^{1,3}$, Stéphane Dauger ${ }^{1,4}$, Marie-Pia d'Ortho $^{1,5}$, Muriel Thoby-Brisson ${ }^{2}$, Jorge Gallego ${ }^{1}$, Boris Matrot ${ }^{1}$

\section{Institutions}

${ }^{1}$ Université de Paris, NeuroDiderot, Inserm, F-75019 Paris, France

${ }^{2}$ Université de Bordeaux, Institut de Neurosciences Cognitives et Intégratives d'Aquitaine, CNRS, Bordeaux, France

${ }^{3}$ Service d'Explorations Fonctionnelles Pédiatriques, AP-HP, Hôpital Robert Debré, F-75019 Paris, France

${ }^{4}$ Service de Médecine intensive-Réanimation pédiatriques, AP-HP, Hôpital Robert Debré, F-75019 Paris, France

${ }^{5}$ Service de Physiologie-Explorations Fonctionnelles, AP-HP, Hôpital Bichat, F-75018 Paris, France

* These authors contributed equally to this work.

\section{Corresponding author}

Jorge Gallego

NeuroDiderot, INSERM, Hôpital Robert Debré, 48 Bd Sérurier, 75019 Paris, France

E-mail: jorge.gallego@inserm.fr

Phone: (33) 140031975

FAX: (33) 140031920

Running title: Obstructive apneas in mice with Phox $2 b$ mutation 


\section{Author contributions}

J.G., B.M., S.D., C.D., M.T.B and M.P.O. conceived and designed the study, and prepared the first draft of the manuscript. B.M. designed and produced the device for apnea measurement and classification, T.B. validated this device and contributed to data analysis. A.M., E.S., M.R. acquired and analyzed respiratory measurements, N.R. generated the mutant mouse lines and supervised statistical analyses. G.P., L.C. and M.T.B., acquired and analyzed the histological and electrophysiological data. All authors contributed to the interpretation of the findings and critically revised the entire manuscript.

\section{Sources of support}

Institutional supports (Inserm and Université de Paris), Fonds de Recherche en Santé Respiratoire (F.R.S.R. grant to A.M.); Association Française du Syndrome d'Ondine (AFSO, grant to E.S.), Legs Poix (Chancellerie des Universités de Paris, grant to C.D.); Fondation pour la recherche Médicale (FRM, grant to M.T.B.). 


\begin{abstract}
Rationale: Congenital Central Hypoventilation Syndrome (CCHS) is characterized by lifethreatening sleep hypoventilation, and is caused by $P H O X 2 B$ gene mutations, most frequently the $\mathrm{PHOX} 2 \mathrm{~B}^{27 \mathrm{Ala} /+}$ mutation, with patients requiring lifelong ventilatory support. It is unclear whether obstructive apneas are part of the syndrome.
\end{abstract}

Objectives: To determine whether Phox $2 b^{27 A l a /+}$ mice, which present the main symptoms of CCHS and die within hours after birth, also express obstructive apneas, and to investigate potential underlying mechanisms.

Methods: Apneas were classified as central, obstructive or mixed by using a novel system combining pneumotachography and laser detection of abdominal movement immediately after birth. Several respiratory nuclei involved in airway patency were examined by immunohistochemistry and electrophysiology in brainstem-spinal cord preparation.

Measurements and Main Results: The median (interquartile range) of obstructive apnea frequency was $2.3 / \mathrm{min}(1.5-3.3)$ in Phox $2 b^{27 A l a /+}$ pups versus $0.6 / \mathrm{min}(0.4-1.0)$ in wildtypes $(P<0.0001)$. Obstructive apnea duration was $2.7 \mathrm{~s}(2.3-3.9)$ in $P h o x 2 b^{27 A l a /+}$ pups versus $1.7 \mathrm{~s}$ (1.1-1.9) in wildtypes $(P<0.0001)$. Central and mixed apneas presented similar, significant differences. In Phox $2 b^{27 A l a /+}$ preparations, the hypoglossal nucleus had fewer $(P<0.05)$ and smaller $(P<0.01)$ neurons, compared to wildtypes. Importantly, coordination of phrenic and hypoglossal motor activities was disrupted, as evidenced by the longer and variable delay of hypoglossal with respect to phrenic activity onset $(P<0.001)$.

Conclusions: The Phox $2 b^{27 A l a /+}$ mutation predisposed pups not only to hypoventilation and central apneas, but also to obstructive and mixed apneas, likely due to hypoglossal dysgenesis. These results thus demand attention towards obstructive events in infants with CCHS.

\title{
Abstract word count: 249
}

Key words: Phox2b; Hypoglossal Nerve; Airway Obstruction; Animals, Newborn. 


\section{Introduction}

Congenital Central Hypoventilation Syndrome (CCHS) is an autosomal dominant disease whose incidence, although unknown precisely, ranges from $1 / 50.000$ to $1 / 200.000$ live births (1). CCHS is characterized by a loss of ventilatory chemosensitivity to hypercapnia and hypoxia, and life-threatening hypoventilation either exclusively during sleep or permanently in the most severe cases. The symptoms are generally noticed at birth or during early infancy. Patients typically require lifelong positive pressure ventilation, at least nocturnally, via tracheostomy during early development, and subsequently, through nasal or facial masks. $\mathrm{CCHS}$ is caused by heterozygous mutations in the paired-like homeobox 2B gene (PHOX2B) (2-4) that encodes a key transcription factor in the development of the autonomic nervous system (5). In $90 \%$ of cases, mutations are tri-nucleotide expansion mutations in $P H O X 2 B$ leading to polyalanine expansions in the gene product (6). The most prevalent mutation is the

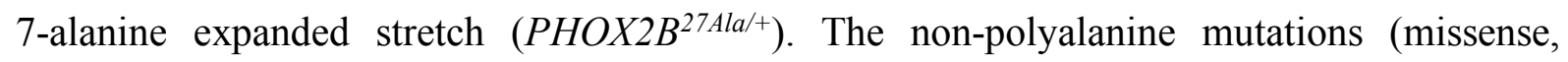
frameshift, nonsense and stop codon mutations) produce even more severe CCHS-related defects, including the need for continuous ventilatory support, Hirschsprung disease and tumors.

Central apneas have been commonly reported in CCHS patients and were assigned to a failure of the central respiratory drive from the brainstem respiratory centers $(7,8)$. Obstructive apneas were occasionally reported in case or small-group studies (9-17) and were considered to require management in $50 \%$ of patients under one year old (18). However, with rare exceptions (19), the study of apneas in CCHS was conducted before the discovery of the disease-causing gene $(2,4)$, and possibly included heterogeneous patient groups. In current practice, obstructive apneas if occurring, may remain unnoticed due to tracheostomy and/or mechanical ventilation, which is generally used in a bi-level positive pressure mode (20). Thus, 
the question of whether obstructive disorders are part of CCHS remains unanswered, which may confound ongoing search for effective pharmacological treatments.

Here, we analyzed whether the Phox $2 b^{27 A l a /+}$ mutation causes obstructive apneas in mice. Previous studies showed that Phox $2 b^{27 A l a /+}$ mice present main CCHS symptoms and die from respiratory arrest within hours after birth (21). Furthermore, the retrotrapezoid nucleus, a cluster of central chemoreceptors providing the major excitatory drive to breathing, is severely depleted $(22,23)$. Accordingly, apneas in Phox $2 b^{27 A l a /+}$ mice were assigned to retrotrapezoid nucleus agenesis and considered to be central in origin. However, the Phox $2 b^{27 A l a /+}$ mutation may also potentiate upper airway obstruction because Phox $2 b$-expressing regions containing hypoglossal premotor neurons may be functionally impaired (24). On this basis, we hypothesized that Phox $2 b^{27 A l a /+}$ pups may express not only central, but also obstructive and mixed apneas. To test this idea, we developed an original method that enables classifying apneas as central, obstructive or mixed in newborn mice. We then analyzed apneas in Phox $2 b^{27 A l a /+}$ pups and sought their neuronal basis by examining late stage fetal Phox $2 b^{27 A l a /+}$ embryos.

\section{Methods}

Word count: 488

\section{Mice}

We generated pups with the constitutive Phox $2 b^{27 A l a /+}$ mutation (21), hereafter termed Phox $2 b^{27 A l a /+}$ pups, and pups with the conditional, tissue-specific Phox $2 b^{27 A l a /+}$ mutation targeted to the retrotrapezoid nucleus (25), hereafter termed Phox $2 b^{27 A l a c o n d /+}$ pups. See online data supplement for the ethical approval and details on mutant generation and genotyping.

\section{Pneumotachography}


Breathing variables were measured using a pneumotachograph and a facemask combined into one single 3D-printed component (termed "pneumotachometer"; Figures 1A and 1B, see details in the online data supplement). The pneumotachometer was calibrated before each monitoring session. The flow signal was integrated for breath-by-breath measurement of tidal volume using a custom-made software. We measured breathing frequency $\left(f_{R}\right.$, number of breaths/min), tidal volume (divided by body weight, $\left.\mathrm{V}_{\mathrm{T}}, \mathrm{mL} / \mathrm{g}\right)$, ventilation $\left(\mathrm{V}_{\mathrm{E}}\right.$, calculated as $\mathrm{f}_{\mathrm{R}} \mathrm{x} \mathrm{V}_{\mathrm{T}}, \mathrm{mL} / \mathrm{g} / \mathrm{min}$ ) and apneas (detailed below). Breathing variables and apneas were analyzed over activity-free periods based on video recordings (Logitech C920, Lausanne, Switzerland), which were considered as corresponding to behavioral sleep.

\section{Laser detection of respiratory efforts}

Abdominal movements were measured using a laser profilometer pointing radially at the lateral abdominal wall (Figures $1 \mathrm{~A}$ and $1 \mathrm{~B}$ ) to detect respiratory efforts during obstructive events (see details in the online data supplement).

\section{Apnea detection and classification}

Apneas were classified as central, obstructive or mixed by adjusting the American Academy of Sleep Medicine recommendations (26) to newborn mice. An apnea was characterized by a $>90 \%$ decrement in peak inspiratory airflow for a duration of at least $0.90 \mathrm{~s}$, which corresponds approximately to two breaths in neonatal mice. The classification into central, obstructive, or mixed apneas was performed by visual inspection of pneumotachometer and laser profilometer signals. An apnea was considered as central when no respiratory effort was present throughout the apnea, as obstructive when associated with continuous respiratory effort, and as mixed when an initial period lacking abdominal movement was followed by resumption of respiratory effort (Figure 1D).

\section{Electrophysiology}


Electrophysiological recordings of rhythmically organized breathing-related activities were performed on isolated brainstem preparations harvested the day before birth (embryonic day 18.5) as previously described (27) (see details in the online data supplement).

\section{Protocol}

Each pup was left with its mother for 15-20 min until the end of maternal care. The pup was then sexed, weighed and attached to the pneumotachometer inside a thermoregulated chamber $\left(32^{\circ} \mathrm{C}\right)$. The snout was sealed into the facemask with polyether adhesive (Impregum, 3M, Saint Paul, MN, USA). Recordings were started within $100 \mathrm{~min}$ following delivery. Breathing variables were recorded for $60 \mathrm{~min}$ (Figure 1E) and extended beyond this period in Phox $2 b^{27 A l a /+}$ pups until terminal apnea to analyze gasping.

\section{Statistics}

For normally distributed data, we used two tailed t-tests and two-way ANOVAs, followed by a Bonferroni's multiple comparisons test where appropriate. Non-normally distributed data were analyzed using the Mann-Whitney test, followed by Dunn's post-hoc multiple comparisons test. Sex had no statistically significant effects in any analysis and will not be mentioned further. All analyses were performed using Prism 9 (GraphPad). $P$ values $<0.05$ were considered significant.

\section{Results}

\section{Baseline breathing and apnea time in $\operatorname{Phox}_{2 b^{27 A l a /+}}$ pups}

The breathing pattern of Phox $2 b^{27 A l a /+}$ pups was typified by significantly reduced ventilation and increased apnea total time (irrespective of apnea type), compared to wildtype pups (Table 1), thereby confirming previous plethysmographic data (21). The lower $\mathrm{V}_{\mathrm{E}}$ of Phox $2 b^{27 A l a /+}$ pups was mainly due to a lower $\mathrm{f}_{\mathrm{R}}$. The $\mathrm{V}_{\mathrm{E}}$-response to hypercapnia was abolished 
in Phox $2 b^{27 A l a /+}$ pups, as previously reported (21) despite a small significant $\mathrm{V}_{\mathrm{T}}$-response (see Figures E2A and E2B in the online data supplement).

\section{Central, obstructive and mixed apneas in $P h o x 2 b^{27 A l a /+}$ pups}

Compared to wildtypes, the Phox $2 b^{27 A l a /+}$ pups expressed significantly more severe central, obstructive and mixed apneas, in terms of mean duration, frequency and total time (Figure 2). The total time for central apneas was longer (Figure 2A) due to both higher apnea occurrence frequencies (Figure 2B), and their longer mean durations (Figure 2C). This result confirmed and extended previous claims that the Phox $2 b^{27 A l a /+}$ mutation causes central apneas (21), but here, based on formal apnea classification. More importantly, the total time for obstructive apneas, which hitherto has never been specifically investigated, was longer in Phox $2 b^{27 A l a /+}$ pups compared to wildtypes (Figure 2A), and this was due to a higher apnea frequency (Figure 2B), and longer mean duration (Figure 2C). A comparison of mixed apneas between Phox $2 b^{27 A l a /+}$ pups and wildtypes yielded the same statistical results as for central and obstructive apneas (Figures 2A-C)

Finally, the proportion of obstructive apneas (with respect to total apnea number) was higher in Phox $2 b^{27 A l a /+}$ pups, compared to wildtype pups $(29 \% \pm 14 v s 23 \% \pm 13$, respectively, $P<0.05$ ), and the proportion of time spent in obstructive apneas (with respect to total apnea time) was also longer in Phox $2 b^{27 A l a /+}$ pups $(31 \% \pm 14 v s 22 \% \pm 13$, respectively, $P<0.001)$.

\section{Obstructed gasping in Phox2 $2 b^{27 A l a /+}$ newborn mice}

We next examined the possibility that airway obstruction contributed to the death of Phox $2 b^{27 A l a /+}$ pups in a subsample of mutant pups $(\mathrm{n}=45)$ in which respiratory monitoring was maintained until respiratory arrest. The occurrence of gasps is illustrated in the recording sequences from a single pup in Figure 3. The initial period during which breathing was variably affected (Figures 3A and 3B), was followed by a period of disorganized breathing interspersed with gasps, which were characterized by large and brief respiratory efforts accompanied by 
large inspirations (Figure 3C). Some of these large abdominal movements were not associated with inspiration, indicating obstructed gasps (Figure 3D). In the 3-min period preceding respiratory arrest, 25 out of the 45 (55\%) pups produced such obstructed gasps.

\section{Implication of retrotrapezoid neuronal loss in apneas}

We asked whether the obstructive pattern of Phox $2 b^{27 A l a /+}$ pups was due to an agenesis of the brainstem retrotrapezoid nucleus, which is the unique neuroanatomical defect reported to date in Phox $2 b^{27 \text { Ala/+ }}$ pups (21). To this end, we replicated the main study in conditional knockin, tissue-specific mice, in which the Phox $2 b^{27 A l a /+}$ mutation was targeted to the retrotrapezoid nucleus region. These mutants, hereafter designated Phox $2 b^{27 \text { Alacond/+ }}$ pups, previously analyzed at postnatal day two, survived normally without apneas, despite the agenesis of retrotrapezoid nucleus and the consequent loss of $\mathrm{CO}_{2}$-chemosensitivity (25). Here, we found that within 100 min after birth, Phox $2 b^{27 \text { Alacond/+ }}$ pups had a lower $\mathrm{V}_{\mathrm{E}}$, mainly due to lower $\mathrm{f}_{\mathrm{R}}$ values, and longer total apnea times (irrespective of apnea type) compared to wildtypes (Table 2). Moreover, the ventilatory response to $\mathrm{CO}_{2}$ was almost abolished in Phox $2 b^{27 \text { Alacond/+ }}$ pups (see Figures E3A and $\mathrm{E} 3 \mathrm{~B}$ in the online data supplement) consistent with a retrotrapezoid neuronal loss. The sole loss of retrotrapezoid neurons in Phox $2 b^{27 \text { Alacond/+ }}$ pups not only increased the frequency and total time of central apneas, but it also increased the mean duration of obstructive apneas compared to wildtypes (Figure 4A-C). No statistical comparison was made between Phox $2 b^{27 A l a /+}$ and Phox $2 b^{27 A l a c o n d /+}$ pups, since these data were collected from two different studies, but an approximate assessment of apnea characteristics in the two mutants clearly indicated that the apneic phenotype was much more severe in Phox $2 b^{27 A l a /+}$ than in Phox $2 b^{27 \text { Alacond/+ }}$ pups. Thus, the exclusive loss of neurons in the retrotrapezoid nucleus promoted central apneas and aggravated obstructive apnea in Phox $2 b^{27 \text { Alacond/+ }}$ pups, but it could not account for the dramatic apneic phenotype of Phox $2 b^{27 A l a /+}$ pups.

Dysgenesis and dysfunction of the hypoglossal nucleus in newborn Phox $2 b^{27 \text { Ala/+ }}$ mice 
Because obstructive and mixed apneas in Phox $2 b^{27 A l a /+}$ pups were not mainly attributable to retrotrapezoid nucleus agenesis, we examined the hypoglossal nucleus, which is the main group of motoneurons involved in the control of the upper airway muscles (28). In Phox $2 b^{27 A l a /+}$ pups, the hypoglossal nucleus displayed an abnormal anatomy (Figures 5A and 5B) characterized by a smaller perimeter (Figure 5C), a reduced surface (Figure 5D), and fewer neurons (Figure 5E), despite having an apparently normal rostrocaudal extension (Figure 5F) and neuroanatomical location (Figure 5G).

To examine whether the function of the hypoglossal nucleus is affected by the Phox $2 b^{27 A l a /+}$ mutation, we recorded spontaneous hypoglossal and phrenic nerve activity in embryonic (E)18.5 isolated brainstem-spinal cord preparations that retain the ability to express respiratory-related phrenic and hypoglossal activities in vitro (27). Electrophysiological monitoring of the hypoglossal nucleus revealed significant functional disorders in Phox $2 b^{27 A l a /+}$ preparations (Figure 6A). Specifically, burst frequency was significantly reduced in Phox $2 b^{27 A l a /+}$ preparations compared to wildtypes (Figure 6B), in line with their reduced breathing frequency in vivo, and the rise time of burst intensity was also reduced, but without significantly affecting burst duration (Figure 6C-E). Most importantly, the combined analysis of hypoglossal and phrenic nerve activities showed a marked loss of coordination between these two neural activities. Specifically, the mutant preparations presented a longer and more variable delay of hypoglossal activity onset with respect to that of the phrenic nerve, which contrasted with the near coincident activities of wildtype preparations (Figures $6 \mathrm{~F}$ and $6 \mathrm{G}$ ). The large intra-individual variability of the delay between hypoglossal and phrenic burst onsets (Figure 6F) was observed in all Phox $2 b^{27 A l a /+}$ preparations, and further pointed to an impairment of the coordination between these activities. 


\section{Discussion}

Here, we show that, compared to wildtypes, newborn mice bearing the Phox $2 b^{27 A l a /+}$ constitutive mutation display an abnormally high degree of not only central but also obstructive and mixed apneas, with the latter tending to be longer than central apneas. Furthermore, terminal apneas were frequently preceded by obstructed gasps, suggesting they play a causal or aggravating role in some pups. The obstructive phenotype of Phox $2 b^{27 A l a /+}$ is ascribed at least partly to dysgenesis and dysfunction of the hypoglossal nucleus, which is critical to the maintenance of upper airway patency.

\section{Methodology for apnea detection and classification in newborn mice}

Our study is the first to discriminate apneas according to type (central, obstructive and mixed) in newborn mice, thanks to an original method that combines a built-in precision pneumotachometer and an ultra-sensitive laser profilometer. Previous attempts to classify apneas in newborn rodents were developed in 7-day old rats using electromyographic electrodes implanted into respiratory muscles under anesthesia (29). This approach was not applicable in the present study due the short lifetime (70\% died within three hours after delivery) and high vulnerability to anesthesia of Phox $2 b^{27 A l a /+}$ mutants (30). Despite our efforts to adjust the facemask to the pups' morphology, the orofacial contact with the mask may have influenced sleep-wake states and breathing. To avoid this effect, we systematically discarded all periods of gross body movements monitored in video recordings to retain behavioral sleep periods only. However, we cannot completely exclude the possibility that some periods of quiet wakefulness were included in our apnea analysis, irrespective of genotype.

A further limitation of our study is that we did not attempt to discriminate sleep states, because, at early postnatal stage examined, this would have required the invasive measure of nuchal EMG (31). Thus, the sleep state-dependence pattern of apnea characteristics was not investigated. Previous studies on 5-day old mice have indicated that active sleep occupies 
approximately $80 \%$ of sleep time, in line with human data (31), thereby suggesting that the apneic patterns described here mainly reflect those that developed during active sleep. Despite these limitations, the present methodology allows the classification of apneas in an infant mouse model of CCHS, with potential applications to other rodent models of sleep disordered breathing in infants.

\section{Apnea profiles in Phox $2 b^{27 A l a /+}$ newborn mice}

As noted above, apneas in Phox $2 b^{27 A l a /+}$ pups were previously ascribed to loss of $\mathrm{CO}_{2}$ driven excitatory input to respiratory rhythm generator by the retrotrapezoid nucleus. All apneas were therefore considered as central. The main result of the present study is that the Phox $2 b^{27 A l a /+}$ mutation not only leads to central apneas, but also to obstructive and mixed apneas. On one hand, central apneas were found to be more frequent than obstructive and mixed apneas, and consequently could be expected to produce more numerous hypoxia-reoxygenation sequences, which are considered to be the main cause of apnea-related morbidity. On the other hand, obstructive and mixed apneas were significantly longer than central apneas, and thus would potentially be associated with larger decreases in heart rate and oxygen saturation (32). Furthermore, the co-occurrence of obstructive events and terminal apnea suggested that obstructive events were responsible for precipitating terminal apnea and death in many Phox $2 b^{27 A l a /+}$ pups. Taken together, these considerations support the conclusion that obstructive events caused by the Phox $2 b^{27 A l a /+}$ mutation may seriously affect morbidity and mortality in the neonatal period.

\section{Neural basis for obstructive apneas in Phox $2 b^{27 A l a /+}$ newborn mice}

The hypoglossal motor nucleus innervates the muscles of the tongue, and therefore withdrawal of an excitatory drive of hypoglossal motoneurons is a common cause of obstructive apneas (28). The dysgenesis of the hypoglossal nucleus found in the present study is a novel result. In previous studies, neuroanatomical defects were sought primarily in Phox $2 b$ - 
expressing structures, leading to the discovery of retrotrapezoid nucleus agenesis (21), without consideration of the hypoglossal nucleus, which does not depend on Phox $2 b$ for its development (24). Our finding of a dysgenesis of the hypoglossal nucleus thus showed that the Phox $2 b^{27 A l a /+}$ mutation elicits non-cell-autonomous mechanisms affecting respiratory networks. To date, such mechanisms were only reported in newborn mice with a non-polyalanine repeat mutation (the frameshift Phox $2 B \triangle 8$ mutation), which expressed a dysfunctional preBötzinger complex, a non-Phox $2 b$ dependent brainstem site that is responsible for respiratory rhythmogenesis (33). Taken together, therefore, these findings widen the range of possible respiratory control disorders caused by Phox $2 b$ mutations.

The neuroanatomical defects of the hypoglossal nucleus were associated with functional defects, the most significant being the uncoupling of hypoglossal and phrenic nerve activities. In normal physiological conditions, the hypoglossal nucleus tends to burst synchronously with the phrenic nerve in order to exert tonic input to the upper airway dilator muscle motor neurons, thereby preventing airway collapse during inspiratory depression $(34,35)$. Here, the onset of hypoglossal discharge was found to be much less well coordinated with diaphragmatic activity in Phox $2 b^{27 A l a /+}$ pups, in contrast to the wildtype. This in turn suggested that, in vivo, the inspiratory negative pressure in Phox $2 b^{27 A l a /+}$ pups is not counteracted by a tonic activation of the upper airway muscles, at least during the initial part of inspiration, thus increasing the propensity for obstructive events. In addition to the likely impact of hypoglossal dysfunction on obstructive events, we also showed that the loss of neurons solely in the retrotrapezoid nucleus was associated with longer obstructive apneas (as shown in Phox2 $2 b^{27 A l a c o n d /+}$ pups). This result thus provides in vivo support for the notion that the retrotrapezoid nucleus makes a significant contribution to the control of genioglossus muscle activity $(36,37)$. Thus, the outcome of hypoglossal and retrotrapezoidal defects acting in combination are likely to further aggravate obstructive apneas in $P$ hox $2 b^{27 A l a /+}$ pups. However, we cannot exclude the possibility 
that hypoglossal activity is also affected by a dysfunction of other brain regions containing hypoglossal premotor neurons expressing Phox $2 b$ and possibly also affected by the mutation (24).

\section{Clinical relevance}

The high incidence of not only central, but also obstructive and mixed apneas in Phox $2 b^{27 A l a /+}$ newborn mice suggested that airway patency disorders also occur in infants with CCHS, but remain undetected due to permanent tracheostomy, and/or the use of positive pressure ventilation. Furthermore, our findings suggest that, if observed, obstructive events should not rule out a diagnosis of CCHS. This study also indicates that obstructive events in patients with CCHS need special attention in the perspective of future treatment research, which to date, has been mainly oriented toward the employment of respiratory stimulants $(38-40)$. Finally, our data shed new light on the neurobiology and neurodevelopment of pharyngeal muscle control, with a potential translation towards pharmacotherapeutic treatment that targets pharyngeal patency and obstructive sleep apnea syndromes.

\section{Conclusion}

We demonstrate that the Phox $2 b^{27 A l a /+}$ mutation, which is the most frequent cause of CCHS, leads to a combination of central, obstructive and mixed apneas in newborn mice. These obstructive disorders are attributable at least in part, to a dysfunction of the hypoglossal nucleus, a non-Phox $2 b$ expressing structure, together with a disruption of input from the Phox $2 b$ expressing retrotrapezoid nucleus. These results broaden the spectrum of neuroanatomical and neurofunctional disorders caused by Phox $2 b$ mutations, and point to the clinical importance of detecting obstructive events in infants with CCHS. 


\section{ACKNOWLEDGEMENTS}

We are deeply indebted to Dr. Florian Brunet, Sebastien Lanteri and Victoria Jean-Baptiste Sérichard for their contribution in developing the apnea detection device, to Fabien Duverger for his contribution to the pneumotachometer design, to Dr. Chih-Wei Hsu and Dr. Mary Dickinson for providing 3D scans of newborn mice, to Charline Riaud and Aurélie Hayotte for experimental assistance and to Dr. John Simmers for English editing.

\section{DISCLOSURE STATEMENT}

- Financial Disclosure: none

- Non-financial Disclosure: none 


\section{References}

1. Bardanzellu F, Pintus MC, Fanos V, Marcialis MA. Neonatal congenital central hypoventilation syndrome: Why we should not sleep on it. Literature review of forty-two neonatal onset cases. Curr Pediatr Rev 2019;15:139-153.

2. Amiel J, Laudier B, Attie-Bitach T, Trang H, de Pontual L, Gener B, Trochet D, Etchevers H, Ray P, Simonneau M, Vekemans M, Munnich A, Gaultier C, Lyonnet S. Polyalanine expansion and frameshift mutations of the paired-like homeobox gene phox $2 b$ in congenital central hypoventilation syndrome. Nat Genet 2003;33:459-461.

3. Matera I, Bachetti T, Puppo F, Di Duca M, Morandi F, Casiraghi G, Cilio M, Hennekam R, Hofstra R, Schöber J, Ravazzolo R, Ottonello G, Ceccherini I. Phox2b mutations and polyalanine expansions corellate with the severity of the respiratory phenotype and associated symptoms in both congenital and late onset central hypoventilation syndrome. J Med Genet 2004;41:373-380.

4. Weese-Mayer DE, Berry-Kravis EM, Zhou L, Maher BS, Silvestri JM, Curran ME, Marazita ML. Idiopathic congenital central hypoventilation syndrome: Analysis of genes pertinent to early autonomic nervous system embryologic development and identification of mutations in phox2b. Am J Med Genet 2003;123A:267-278.

5. Brunet JF, Pattyn A. Phox2 genes - from patterning to connectivity. Curr Opin Genet Dev 2002;12:435-440.

6. Weese-Mayer DE, Berry-Kravis EM, Ceccherini I, Keens TG, Loghmanee DA, Trang H. An official ats clinical policy statement: Congenital central hypoventilation syndrome: Genetic basis, diagnosis, and management. Am J Respir Crit Care Med 2010;181:626-644.

7. Huang J, Colrain IM, Panitch HB, Tapia IE, Schwartz MS, Samuel J, Pepe M, Bandla P, Bradford R, Mosse YP, Maris JM, Marcus CL. Effect of sleep stage on breathing in children with central hypoventilation. J Appl Physiol (1985) 2008;105:44-53. 
8. Cielo C, Marcus CL. Central hypoventilation syndromes. Sleep Med Clin 2014;9:105-118.

9. Weese-Mayer DE, Berry-Kravis EM, Zhou L. Adult identified with congenital central hypoventilation syndrome--mutation in phox $2 \mathrm{~b}$ gene and late-onset chs. Am J Respir Crit Care Med 2005;171:88.

10. Bygarski E, Paterson M, Lemire EG. Extreme intra-familial variability of congenital central hypoventilation syndrome: A case series. J Med Case Rep 2013;7:117.

11. Katwa U, D'Gama AM, Qualls AE, Donovan LM, Heffernan J, Shi J, Agrawal PB. Atypical presentations associated with non-polyalanine repeat phox $2 \mathrm{~b}$ mutations. Am $J$ Med Genet A 2018;176:1627-1631.

12. Kurz H, Sterniste W, Dremsek P. Resolution of obstructive sleep apnea syndrome after adenoidectomy in congenital central hypoventilation syndrome. Pediatr Pulmonol 1999;27:341-346.

13. Amimoto Y, Okada K, Nakano H, Sasaki A, Hayasaka K, Odajima H. A case of congenital central hypoventilation syndrome with a novel mutation of the phox $2 \mathrm{~b}$ gene presenting as central sleep apnea. J Clin Sleep Med 2014;10:327-329.

14. Byers HM, Chen M, Gelfand AS, Ong B, Jendras M, Glass IA. Expanding the phenotype of congenital central hypoventilation syndrome impacts management decisions. Am J Med Genet A 2018;176:1398-1404.

15. Silvestri JM, Chen ML, Weese-Mayer DE, McQuitty JM, Carveth HJ, Nielson DW, Borowitz D, Cerny F. Idiopathic congenital central hypoventilation syndrome: The next generation. Am J Med Genet 2002;112:46-50.

16. Emanuel H, Rennie K, Macdonald K, Yadav A, Mosquera RA. Screening children with a family history of central congenital hypoventilation syndrome. Case Rep Pediatr 2020;2020:2713606. 
17. Mahmoud M, Bryan Y, Gunter J, Kreeger RN, Sadhasivam S. Anesthetic implications of undiagnosed late onset central hypoventilation syndrome in a child: From elective tonsillectomy to tracheostomy. Paediatr Anaesth 2007;17:1001-1005.

18. Olson TS, Woodson GE, Heldt GP. Upper airway function in ondine's curse. Arch Otolaryngol Head Neck Surg 1992;118:310-312.

19. Kasi AS, Kun SS, Keens TG, Perez IA. Adult with phox $2 b$ mutation and late-onset congenital central hypoventilation syndrome. J Clin Sleep Med 2018;14:2079-2081.

20. Chen ML, Keens TG. Congenital central hypoventilation syndrome: Not just another rare disorder. Paediatr Respir Rev 2004;5:182-189.

21. Dubreuil V, Ramanantsoa N, Trochet D, Vaubourg V, Amiel J, Gallego J, Brunet JF, Goridis C. A human mutation in phox $2 \mathrm{~b}$ causes lack of co 2 chemosensitivity, fatal central apnea, and specific loss of parafacial neurons. Proc Natl Acad Sci U S A 2008;105:10671072.

22. Guyenet PG, Stornetta RL, Souza G, Abbott SBG, Shi Y, Bayliss DA. The retrotrapezoid nucleus: Central chemoreceptor and regulator of breathing automaticity. Trends Neurosci 2019;42:807-824.

23. Guyenet PG, Bayliss DA, Stornetta RL, Ludwig MG, Kumar NN, Shi Y, Burke PG, Kanbar R, Basting TM, Holloway BB, Wenker IC. Proton detection and breathing regulation by the retrotrapezoid nucleus. $J$ Physiol 2016;594:1529-1551.

24. Kang BJ, Chang DA, Mackay DD, West GH, Moreira TS, Takakura AC, Gwilt JM, Guyenet PG, Stornetta RL. Central nervous system distribution of the transcription factor phox $2 b$ in the adult rat. J Comp Neurol 2007;503:627-641.

25. Ramanantsoa N, Hirsch MR, Thoby-Brisson M, Dubreuil V, Bouvier J, Ruffault PL, Matrot B, Fortin G, Brunet JF, Gallego J, Goridis C. Breathing without co(2) chemosensitivity in conditional phox2b mutants. J Neurosci 2011;31:12880-12888. 
26. Berry R, Brook R, Gamaldo C, Harding S, Lloyd R, Quan S, Troester M, Vaughn B. The AASM manual for the scoring of sleep and associated events: Rules, terminology, and technical specifications.; 2017.

27. Dubois CJ, Cardoit L, Schwarz V, Markkanen M, Airaksinen MS, Uvarov P, Simmers J, Thoby-Brisson M. Role of the $\mathrm{k}(+)-\mathrm{cl}(-)$ cotransporter $\mathrm{kcc} 2 \mathrm{a}$ isoform in mammalian respiration at birth. eNeuro 2018;5.

28. Horner RL. Emerging principles and neural substrates underlying tonic sleep-statedependent influences on respiratory motor activity. Philos Trans R Soc Lond B Biol Sci $2009 ; 364: 2553-2564$.

29. Kidder IJ, Mudery JA, Bailey EF. Neural drive to respiratory muscles in the spontaneously breathingrat pup. Respiratory Physiology \& Neurobiology 2014;202:64-70.

30. Bourgeois T, Ringot M, Ramanantsoa N, Matrot B, Dauger S, Delclaux C, Gallego J. Breathing under anesthesia: A key role for the retrotrapezoid nucleus revealed by conditional phox2b mutant mice. Anesthesiology 2019;130:995-1006.

31. Durand E, Dauger S, Pattyn A, Gaultier C, Goridis C, Gallego J. Sleep-disordered breathing in newborn mice heterozygous for the transcription factor phox $2 \mathrm{~b}$. Am J Respir Crit Care Med 2005;172:238-243.

32. Muttitt SC, Finer NN, Tierney AJ, Rossmann J. Neonatal apnea: Diagnosis by nurse versus computer. Pediatrics 1988;82:713-720.

33. Alzate-Correa D, Mei-Ling Liu J, Jones M, Silva TM, Alves MJ, Burke E, Zuniga J, Kaya B, Zaza G, Aslan MT, Blackburn J, Shimada MY, Fernandes-Junior SA, Baer LA, Stanford KI, Kempton A, Smith S, Szujewski CC, Silbaugh A, Viemari JC, Takakura AC, Garcia AJ, 3rd, Moreira TS, Czeisler CM, Otero JJ. Neonatal apneic phenotype in a murine congenital central hypoventilation syndrome model is induced through non-cell autonomous developmental mechanisms. Brain Pathol 2021;31:84-102. 
34. Chamberlin NL, Eikermann M, Fassbender P, White DP, Malhotra A. Genioglossus premotoneurons and the negative pressure reflex in rats. $J$ Physiol 2007;579:515-526.

35. Horner RL, Hughes SW, Malhotra A. State-dependent and reflex drives to the upper airway: Basic physiology with clinical implications. J Appl Physiol (1985) 2014;116:325336.

36. Silva JN, Lucena EV, Silva TM, Damasceno RS, Takakura AC, Moreira TS. Inhibition of the pontine kolliker-fuse nucleus reduces genioglossal activity elicited by stimulation of the retrotrapezoid chemoreceptor neurons. Neuroscience 2016;328:9-21.

37. Dutschmann M, Herbert H. The kolliker-fuse nucleus gates the postinspiratory phase of the respiratory cycle to control inspiratory off-switch and upper airway resistance in rat. Eur J Neurosci 2006;24:1071-1084.

38. Nattie E. Ondine undone. N Engl J Med 2015;373:573-575.

39. Weese-Mayer DE, Silvestri JM, Menzies LJ, Morrow-Kenny AS, Hunt CE, Hauptman SA. Congenital central hypoventilation syndrome: Diagnosis, management, and long-term outcome in thirty-two children. J Pediatr 1992;120:381-387.

40. Di Lascio S, Benfante R, Cardani S, Fornasari D. Research advances on therapeutic approaches to congenital central hypoventilation syndrome (cchs). Front Neurosci $2020 ; 14: 615666$. 


\section{FIGURE LEGENDS}

Figure 1. Experimental setup for detection and classification of central, obstructive and mixed apneas in newborn mice. $(A)$ Technical drawing of the 'pneumotachometer' incorporating a Fleisch pneumotachograph and a facial mask that was fixed on the pup's snout. Air flow through the mask $\left(20 \mathrm{~mL} / \mathrm{min}^{-1}\right)$ prevented rebreathing. A laser profilometer detected abdominal movements within a $2 \mathrm{~mm} \times 0.5 \mathrm{~mm}$ zone (black rectangle). (B) Image from video recording showing the facemask and the laser beam. The entire setup was placed in a thermoregulated chamber (not shown). (C) Individual traces of flow signal from the pneumotachograph (upper trace) and movement monitored by laser profilometry (lower trace) from a pup. $(D)$ Examples of central (no flow, no movement), obstructive (no flow, abdominal movement) and mixed (no flow, abdominal movement at the end of apnea) in a Phox $2 b^{27 A l a /+}$ pup. (E) Experimental protocol. After 5 min of air breathing, each pup was exposed to $8 \% \mathrm{CO}_{2}$, and then back to air for 50 min recording. Apneas were classified as central, obstructive or mixed from minute 12 to minute 60 .

Figure 2. The Phox $2 b^{27 A l a /+}$ mutation enhanced central, obstructive and mixed apneas in newborn pups compared to wildtypes. Apneas were quantified according to Total time $(A)$ calculated as the ratio of total apnea durations divided by recording time after exclusion of activity periods, Apnea frequency $(B)$, and Apnea mean duration $(C)$. Undetermined apneas represented less than $2 \%$ of total apnea time in either group and were not considered. The high interindividual variability in the apnea characteristics of mutants reflected their variable lifetime, which ranged from a few minutes to 24 hours. Lines and whiskers in boxplots represent medians, interquartile ranges, and minimum and maximum values. ${ }^{*} P=0.0129,{ }^{*} * * P<0.0001$ indicate significant differences.

Figure 3. Examples of unobstructed and obstructed terminal gasps in a Phox $2 b^{27 A l a /+}$ pup. $(A)$ Slow, regular breathing. $(B)$ Breathing interspersed with apneas. $(C)$ Irregular breathing with 
apneas and an unobstructed gasp accompanied by an abdominal expansion (arrows). (D) Long obstructive apnea followed by two obstructed gasps (arrows). The four excerpts in $(A-D)$ were recorded in the same Phox $2 b^{27 A l a /+}$ pup after $3 \mathrm{~h} 02,4 \mathrm{~h} 15,4 \mathrm{~h} 22$ and $4 \mathrm{~h} 52$ of recording, respectively.

Figure 4. The conditional, tissue-specific Phox $2 b^{27 \text { Alacond/+ }}$ mutation enhanced central and obstructive apnea expression compared to wildtypes. Apneas were quantified by Total time $(A)$ calculated as the ratio of total apnea durations divided by the recording time after the exclusion of activity periods, Apnea frequency $(B)$, and Mean duration $(C)$. Lines and whiskers in boxplots represent medians, the interquartile ranges, and the minimum and maximum values. Compared with Phox $2 b^{27 A l a /+}$ pups (Figure 2), the apneic phenotype of Phox $2 b^{27 \text { Alacond/+ }}$ was much less severe. ${ }^{*} P<0.05,{ }^{* * *} P<0.001$ indicate significant differences, ns indicates no statistical difference.

Figure 5. Abnormal anatomy of the hypoglossal nucleus in the Phox $2 b^{27 A l a /+}$ mutant. (A) Schematic representations of an isolated brainstem preparation (left), a coronal brainstem slice (right, top) and a sagittal brainstem slice (right, bottom) with the corresponding position of the retrotrapezoid nucleus (RTN; red shading), the preBötzinger complex (preBötC; orange shading) and the hypoglossal (XII) nucleus (gray shading). The double-headed violet arrows indicate the coronal (1) and sagittal (2) plans of section. The violet rectangles delimit the areas shown in B. (B) Immunostainings against Islet1,2 (green) in $30 \mu \mathrm{m}$ thick brainstem coronal (top) and sagittal (bottom) slices obtained from embryonic day $18.5 \mathrm{WT}$ and Phox $2 b^{27 A l a /+}$ embryos. White lines delimit the XII nuclei. $(C-G)$ Histograms showing overall mean values $( \pm$ SEM) for the XII nucleus perimeter $(C)$ and surface $(D)$, the number of neurons per XII nucleus $(E)$, the rostro-caudal extension distance $(F)$ and the position relative to the caudal end of the VII nucleus $(G)$ of the XII nucleus measured from WT (green) and Phox $2 b^{27 \text { Ala/t }}$ (blue) 
embryos. The number of preparations analyzed is indicated in each bar graph. $* P<0.05, * * P$ $<0.01$ indicate significant differences (t-test), ns indicates no statistical difference. In the mutant, the XII nucleus is smaller, contains less neurons but with the same rostro-caudal extension and position relative to the VII nucleus. C4: phrenic rootlet, RTN: retrotrapezoïd nucleus, preBötC: preBötzinger complex, VII: facial nucleus, XII: hypoglossal nucleus, WT: wildtype.

Figure 6. The hypoglossal nerve is functional but the shape of its bursts and their coordination with phrenic nerve activity are altered in the Phox $2 b^{27 A l a /+}$ mutant. (A) Left, Schematic representation of an isolated brainstem preparation with the arrangement for simultaneous electrophysiological recording of hypoglossal and phrenic nerve activities. Right, Representative rectified and integrated (Int) simultaneous recordings from hypoglossal (XII) and phrenic (C4) ventral roots in in vitro preparations obtained from wildtype (WT, green traces) and a mutant (Phox $2 b^{27 A l a /+}$, blue traces) mice. (B) Histograms showing mean XII burst frequency in $12 \mathrm{WT}$ (green) and 9 Phox $2 b^{27 A l a /+}$ (blue) preparations. (C) Superimposed XII bursts and average traces (bold line) from representative recordings of a WT ( $\mathrm{n}=10$ bursts, green) and a Phox $2 b^{27 A l a /+}(\mathrm{n}=12$ bursts, blue) preparation. $(D)$ and $(E)$ Histograms showing mean rise times and durations of XII bursts in WT $\left(n=120\right.$ events, green) and Phox $2 b^{27 A l a /+}(\mathrm{n}$ $=90$ events, blue) recordings. $(F)$ Superimposition of spontaneous hypoglossal (top, $\mathrm{n}=10$ bursts) and phrenic (bottom, $\mathrm{n}=12$ bursts) motor bursts recorded from a WT (green) and a Phox $2 b^{27 A l a /+}$ (blue) preparation. The dotted lines indicate the mean onset of the phrenic bursts. Note that the coordination between phrenic and hypoglossal burst onsets is affected in the Phox $2 b^{27 A l a /+}$ preparations. $(G)$ Boxplots with whiskers (min to max) representing the mean delay ( \pm SEM) between phrenic and hypoglossal bursts. Hypoglossal bursts were initiated later than phrenic bursts in the $P h o x 2 b^{27 A l a /+}$ preparations and over a wider range of values. $* * P<$ $0.01, * * * P<0.001$ indicate significant differences (Mann-Whitney t-test), ns indicates no 
bioRxiv preprint doi: https://doi.org/10.1101/2021.02.15.431285; this version posted April 9, 2021. The copyright holder for this preprint (which was not certified by peer review) is the author/funder. All rights reserved. No reuse allowed without permission.

statistical difference. C4: phrenic rootlet, RTN: retrotrapezoïd nucleus, preBötC: preBötzinger complex, XII: hypoglossal nucleus, WT: wildtype. 


\section{TABLE 1}

\begin{tabular}{|l|c|c|c|}
\hline Variable & Wildtype & Phox $2 b^{27 \text { Ala } /+}$ & $P$ value \\
\hline Weight $(\mathrm{g})$ & $1.33 \pm 0.09$ & $1.28 \pm 0.1$ & 0.007 \\
\hline Movement time (s/min) & $24 \pm 7$ & $15 \pm 8$ & $<0.001$ \\
\hline $\mathrm{f}_{\mathrm{R}}(\mathrm{breaths} / \mathrm{min})$ & $98 \pm 18$ & $46 \pm 19$ & $<0.001$ \\
\hline $\mathrm{V}_{\mathrm{T}}\left(\mathrm{mL} / \mathrm{g} \times 10^{-3}\right)$ & $6.7 \pm 0.9$ & $6.3 \pm 1.4$ & 0.104 \\
\hline $\mathrm{V}_{\mathrm{E}}(\mathrm{mL} / \mathrm{min} / \mathrm{g})$ & $0.65 \pm 0.13$ & $0.29 \pm 0.16$ & $<0.001$ \\
\hline Apnea time (s/min) & $7.22 \pm 4.60$ & $26.67 \pm 12.79$ & $<0.001$ \\
\hline
\end{tabular}

Table 1. Baseline breathing variables in constitutive Phox $2 b^{27 A l a /+}$ newborn mice and wildtype controls. Data were collected from minute 12 to minute 60 of the protocol. Movement time was expressed in seconds per minute of recording time. $\mathrm{f}_{\mathrm{R}}$ : breathing frequency; $\mathrm{V}_{\mathrm{T}}$ : tidal volume; $\mathrm{V}_{\mathrm{E}}$ : mean ventilation. Apnea time was expressed in seconds per minute of movement-free time (corresponding to sleep), and calculated irrespective of apnea type. $P$ values: t-test comparison between mutants and wildtypes. Values are means \pm SD. 
TABLE 2

\begin{tabular}{|l|c|c|c|}
\hline Variable & Wildtype & Phox $2 b^{27 \text { Alacond } /+}$ & $P$ value \\
\hline Weight $(\mathrm{g})$ & $1.31 \pm 0.12$ & $1.35 \pm 0.10$ & 0.0198 \\
\hline Movement time (s/min) & $27 \pm 10$ & $24 \pm 8$ & 0.049 \\
\hline $\mathrm{f}_{\mathrm{R}}(\mathrm{breaths} / \mathrm{min})$ & $97 \pm 28$ & $79 \pm 24$ & $<0.001$ \\
\hline $\mathrm{V}_{\mathrm{T}}\left(\mathrm{mL} / \mathrm{g} \times 10^{-3}\right)$ & $6.6 \pm 0.9$ & $6.3 \pm 0.8$ & 0.079 \\
\hline $\mathrm{V}_{\mathrm{E}}(\mathrm{mL} / \mathrm{min} / \mathrm{g})$ & $0.64 \pm 0.19$ & $0.49 \pm 0.14$ & $<0.001$ \\
\hline Apnea time (s/min) & $8.08 \pm 5.92$ & $11.34 \pm 8.62$ & 0.017 \\
\hline
\end{tabular}

Table 2. Baseline breathing variables in conditional tissue-specific Phox $2 b^{27 \text { Alacond/+ }}$ newborn mice and wildtype controls. Data were collected from minute 12 to minute 60 of the protocol. Movement time was expressed in seconds per minute of recording time. $f_{R}$ : breathing frequency; $\mathrm{V}_{\mathrm{T}}$ : tidal volume; $\mathrm{V}_{\mathrm{E}}$ : mean ventilation. Apnea time (in seconds per minute of movement-free time) was calculated irrespective of apnea type. $P$ values: t-test comparisons between mutants and wildtypes. Values are means \pm SD. 
FIGURE 1

A

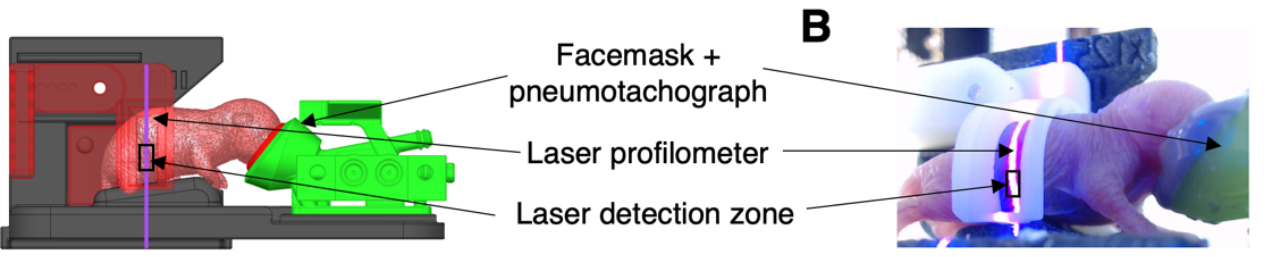

C
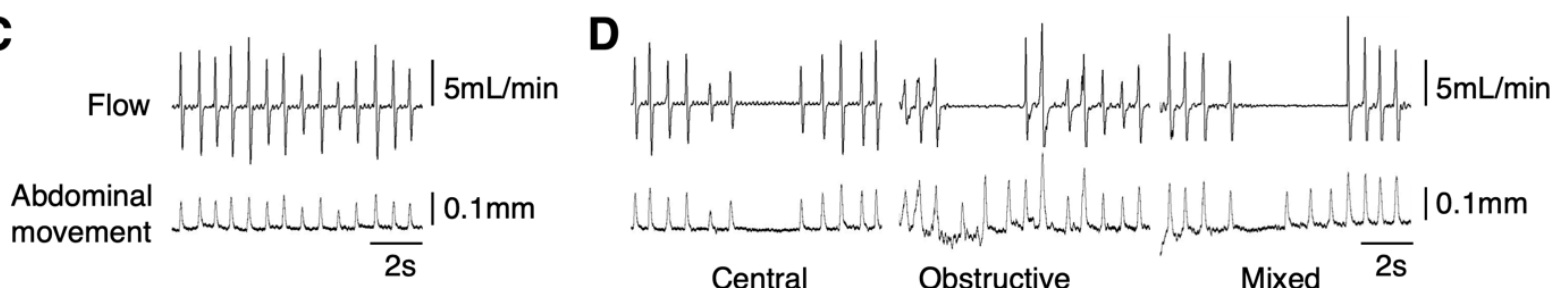

$\mathbf{E}$

\begin{tabular}{|l|cc|ccc|}
\hline AIR & $8 \% \mathrm{CO}_{2}$ & & AIR & 60 \\
\hline
\end{tabular}


FIGURE 2

A

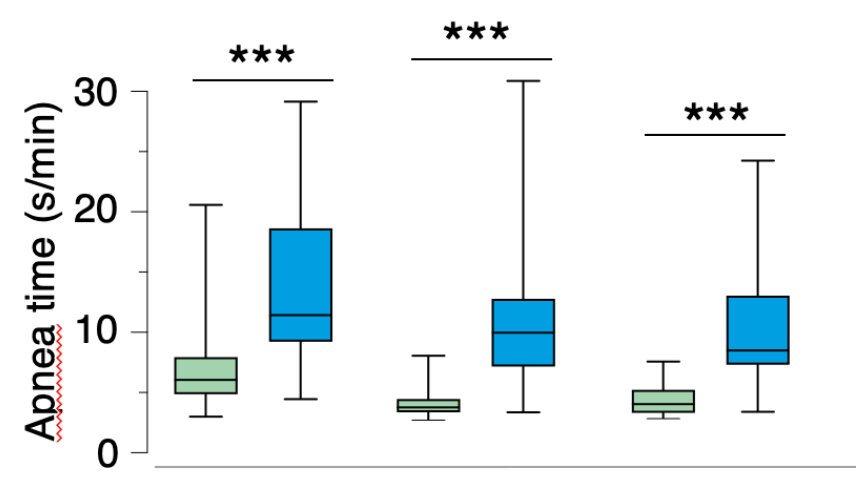

B

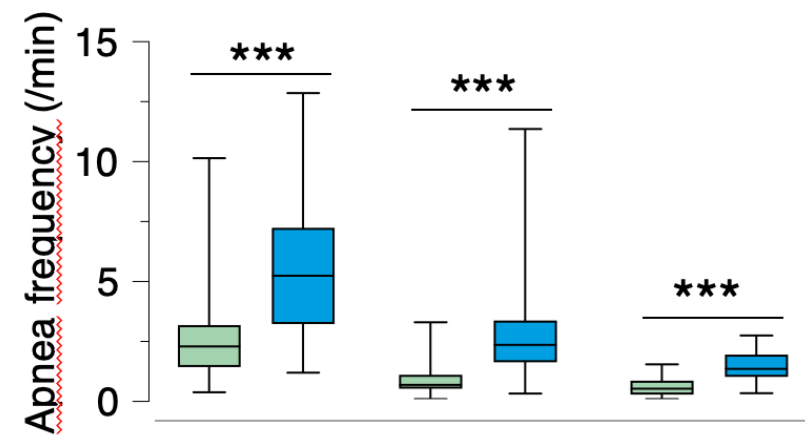

C

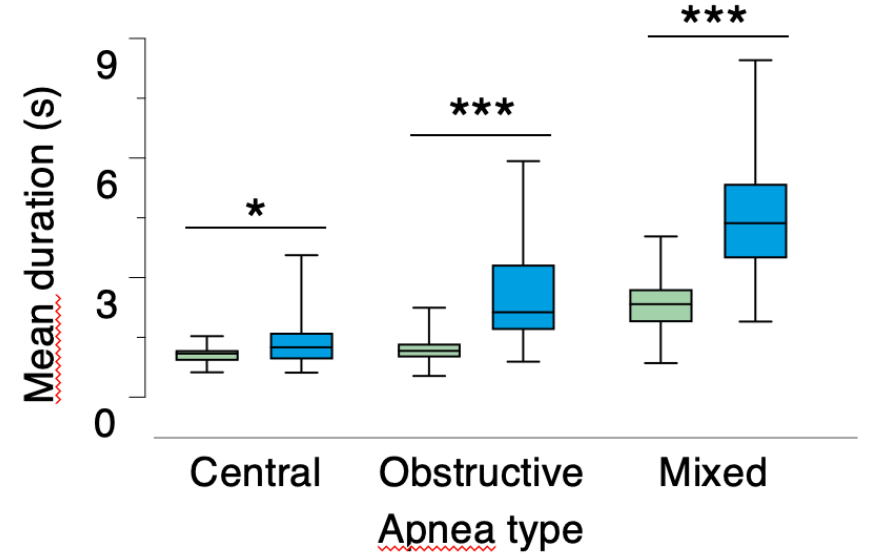


FIGURE 3

A

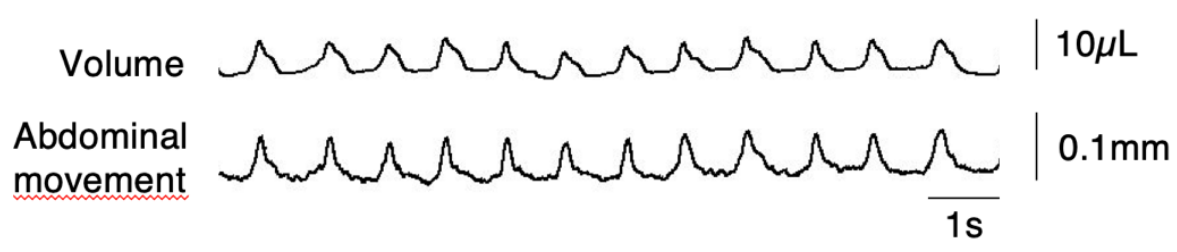

B
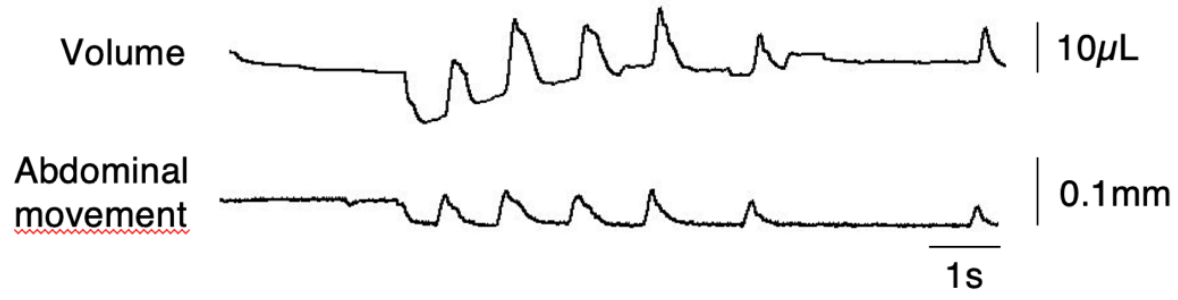

C

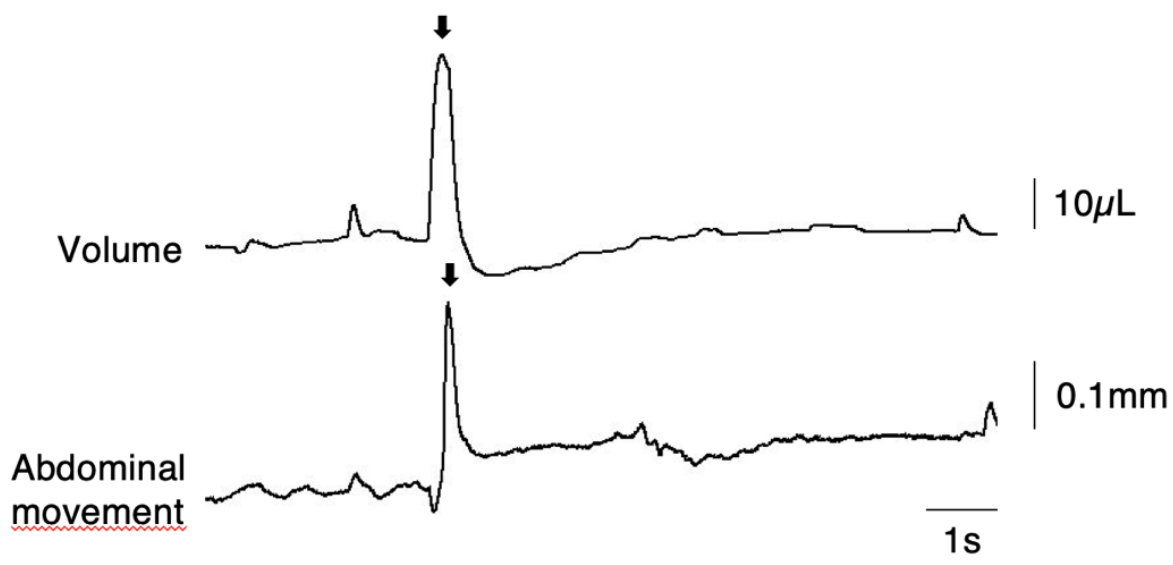

D

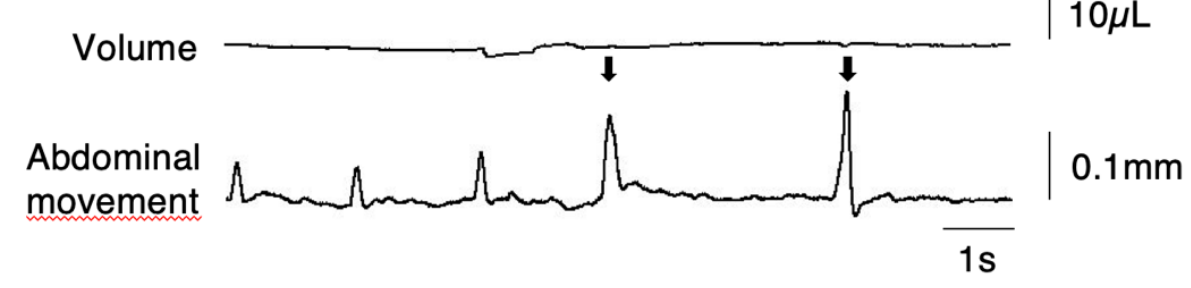


FIGURE 4

Wildtype $(\mathrm{n}=62)$

$\square$ Phox2b 27 Alacond/++ $(\mathrm{n}=58)$
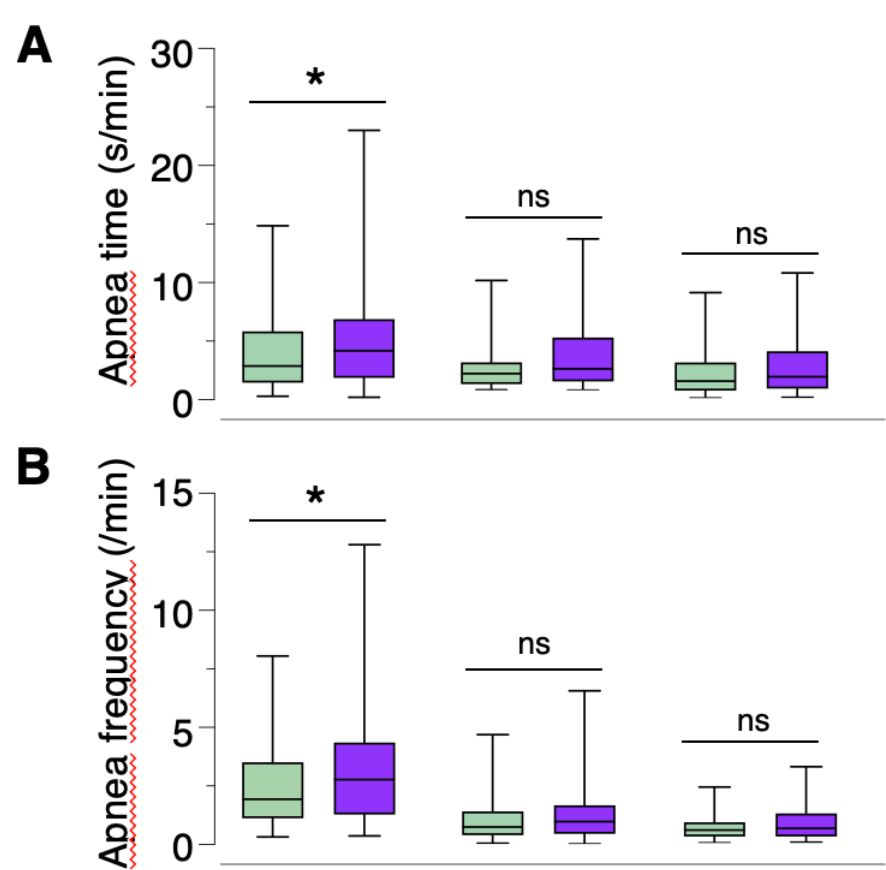

C

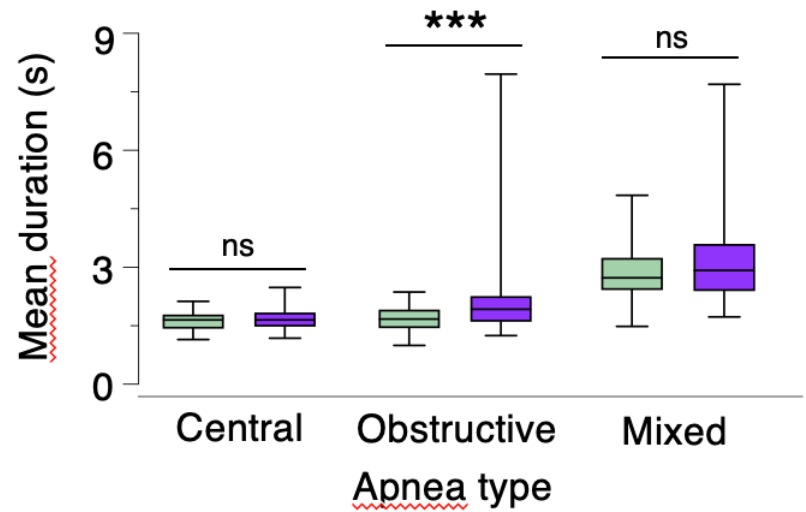




\section{FIGURE 5}
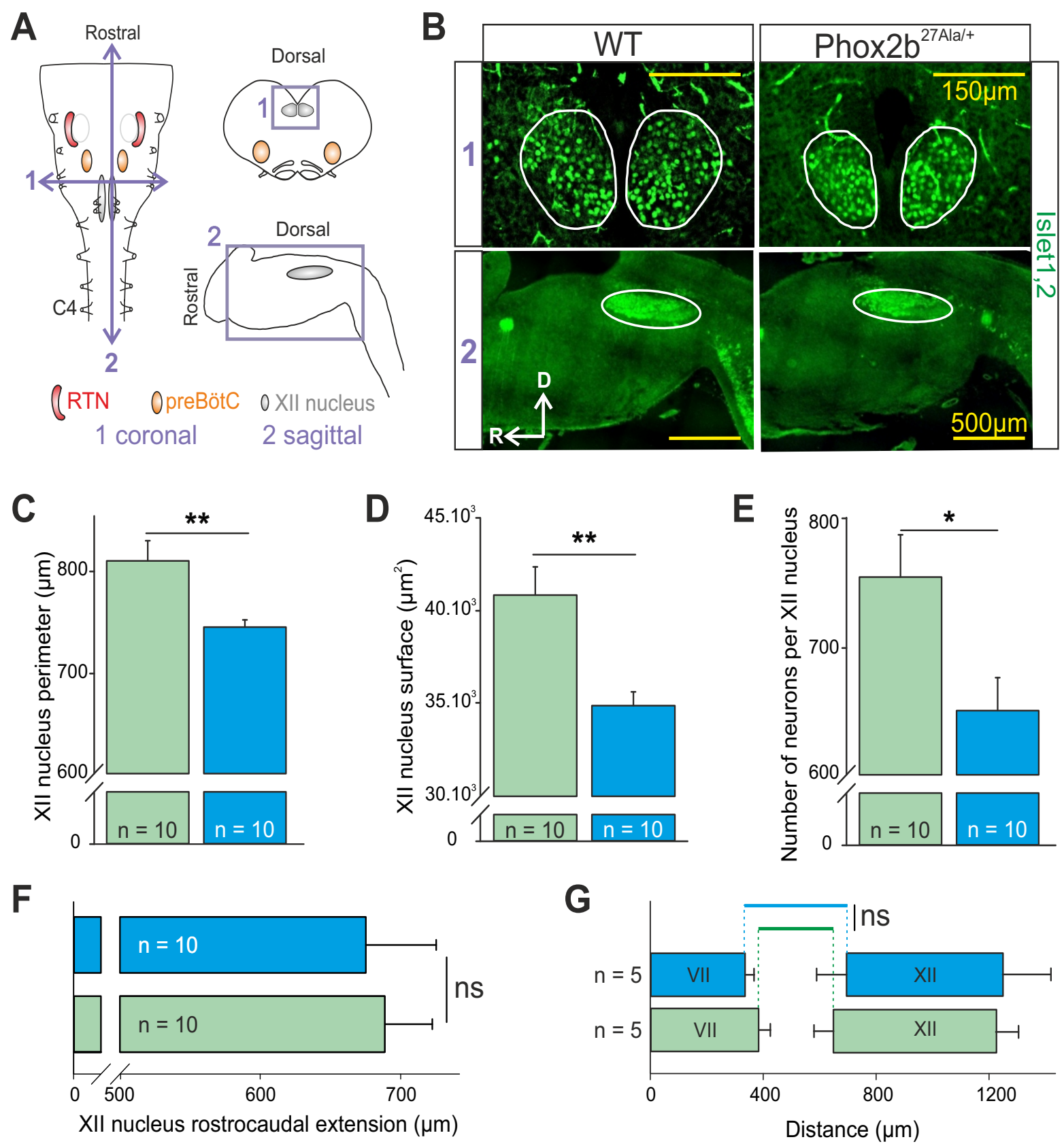

$\square$ WT $\quad \square$ Phox2b $\mathrm{b}^{27 \mathrm{Ala} /+}$ 
FIGURE 6

A

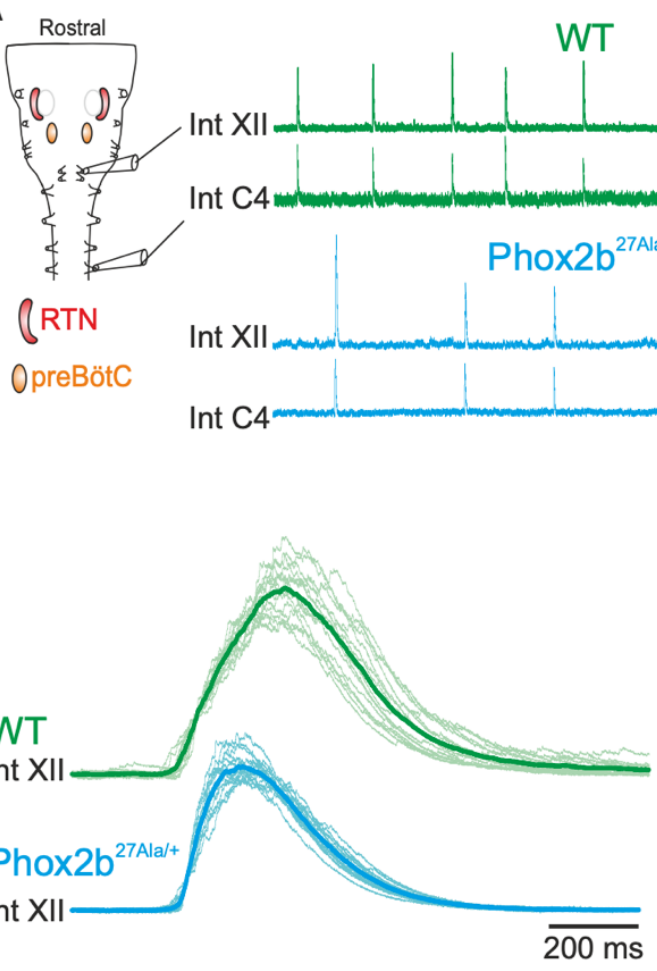

B

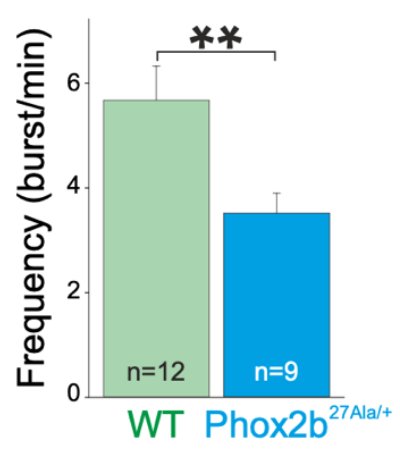

E
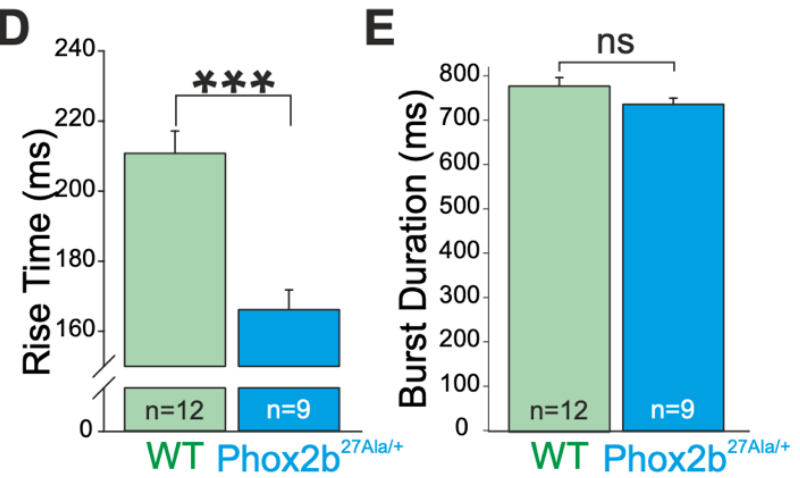

F

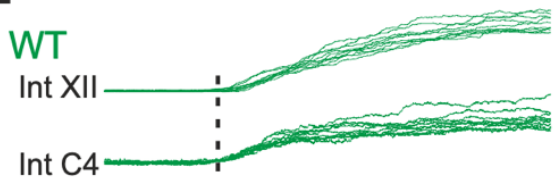

Phox $2 b^{27 A l a /+}$ Int XII ! Int C4

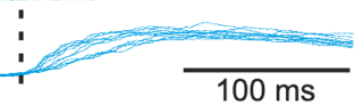

G

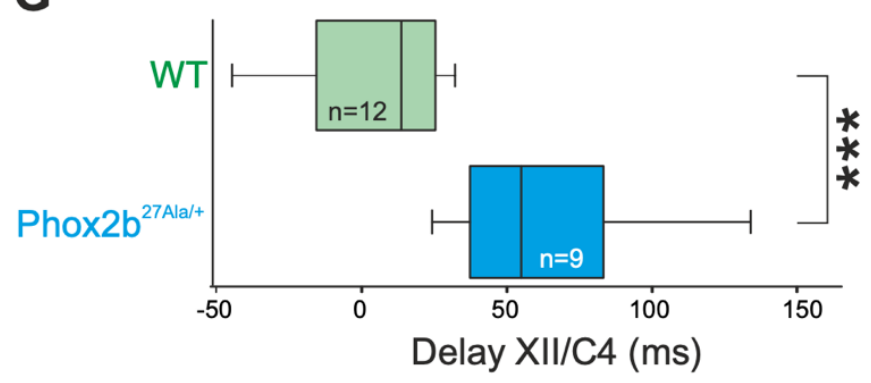

